\title{
Ten-year review of the clinical presentation and treatment outcome of Asherman's syndrome in university of Maiduguri teaching hospital, Borno State, Nigeria
}

\author{
Ado Danazumi Geidam ${ }^{1 *}$, Adamu Malgwi²
}

\begin{abstract}
${ }^{1}$ Department of Obstetrics and Gynaecology, College of Medical Sciences, University of Maiduguri, Borno State, Nigeria,

${ }^{2}$ Department of Obstetrics and Gynaecology, University of Maiduguri Teaching Hospital, Maiduguri, Borno State, Nigeria
\end{abstract}

Received: 03 January 2022

Accepted: 31 January 2022

\section{*Correspondence:}

Dr. Ado Danazumi Geidam,

E-mail: adogeidam@yahoo.com

Copyright: () the author(s), publisher and licensee Medip Academy. This is an open-access article distributed under the terms of the Creative Commons Attribution Non-Commercial License, which permits unrestricted non-commercial use, distribution, and reproduction in any medium, provided the original work is properly cited.

\begin{abstract}
Background: Asherman's syndrome (AS) is an important gynaecological disorder characterized by a menstrual abnormality (hypomenorrhea/amenorrhea) and infertility that is usually caused by activities that traumatize the endometrium. Objective of current study was to determine the prevalence, clinical presentation and treatment outcome of Asherman's syndrome in our hospital.

Methods: A retrospective review of patients with Asherman's syndrome managed at the University of Maiduguri Teaching hospital over 10 years (January 2008 to December 2017). Data about the patients were obtained and analyzed using Microsoft office excel 2007 and SPSS version 25 (IBM SPSS, Statistics) to generate descriptive statistics (frequencies, ratio and percentages) which were presented as tables.

Results: The prevalence of AS is 5.3\%. Most of the patients were in the 25-34 age group (69.1\%) and the majority $(94.5 \%)$ were married. Dilatation and curettage (D \& C) constituted the commonest risk factor for Asherman's syndrome $(21 / 55,38.2 \%)$ and infertility alone $(29,52.7 \%)$, and hypomenorrhea with infertility $10(18.2 \%)$ were the commonest presentation. Twenty-five percent of the patients (14/55) achieved normal menses and $11(20 \%)$ achieved pregnancy following treatment.

Conclusions: AS is not uncommon in our environment. D\&C is the commonest risk factor and the patients usually present with infertility and hypomenorrhea.
\end{abstract}

Keywords: Asherman's syndrome, Achieve pregnancy, D and C, Infertility, UMTH

\section{INTRODUCTION}

Adhesion within the endometrial cavity is known as intrauterine adhesion or uterine synechiae. When it is associated with hypomenorrhea or amenorrhea, it is called Asherman's syndrome (AS). ${ }^{1,2}$ The true incidence of AS is unknown, as is dependent on the population studied and classification system used. ${ }^{3,4}$ However it is steadily increasing particularly where dilation and curettage is still the most common method of pregnancy termination. $^{5,6}$ An incidence of $1.6 \%, 29.2 \%, 4.2 \%$ has been reported in Abuja, Lagos, Uyo, respectively. 3,4,6

The destruction of the basal is endometrium by trauma prevent endometrial thickening in response to ovarian steroids, leading to a spectrum of avascular scarring 
which ranges from filmy adhesion, dense bands or complete obliteration. ${ }^{1-5}$ Vigorous curettage of the uterine cavity following a pregnancy complicated by infection is the commonest cause of Asherman's syndrome, ${ }^{6}$ and earlier studies have shown that intrauterine adhesion was found in $25 \%$ of women who had dilation and curettage in the postpartum period, in $30.9 \%$ following missed abortion and $40 \%$ in those that had dilatation and curettage for retained products of conception after miscarriage or retained placenta. The risk also increases with the number of dilatation and curettage performed as $16 \%$ is recorded after the first dilatation and $32 \%$ after three or more. ${ }^{3,4}$ Other documented risk factors include evacuation of hydatidiform mole, caesarean section, myomectomy, metroplasty, diagnostic curettage in a nongravid uterus, B-lynch, uterine artery embolisation, hysteroscopic surgery, insertion of intrauterine device complicated by infection, pelvic radiation, endometrial ablation, tuberculous endometritis, schistosomiasis endometritis and manual removal of placenta. ${ }^{1-8}$

The clinical presentation of patients with Asherman's syndrome include menstrual abnormalities presenting as hypomenorrhea or secondary amenorrhea, others are; lower abdominal pain, dysmenorrhea, subfertility, recurrent miscarriage, fetal malposition and adherent placenta. Diagnosis requires a high index of suspicion with hysteroscopy being the gold standard, where direct visualization under magnification of the uterine cavity is possible. Transvaginal ultrasonography/3D USS, saline infusion sonography, hysterosalpingography and Magnetic resonance Imaging are other methods of diagnosis. ${ }^{1-9}$ The diagnostic and clinical presentation has been used by different authorities to classify Asherman's syndrome based on severity. The commonly used are classification by The American fertility society who classifies it into minimal/mild, moderate and severe, Hamou et al classify it into isthmic, marginal, central and severe. Other classifications were by Nasr et al and the former European society for hysteroscopy. ${ }^{10}$ Treatment is aimed at restoring the endometrial cavity size, shape and prevention of adhesion reformation leading to normal function and possibly increasing the chances of pregnancy in patients that present with subfertility. These are achievable by direct vision-hysteroscopic adhesiolysis (gold standard) or through blind adhesiolysis. This procedure can be primary when first attempt at adhesiolysis is carried out or secondary when a repeat adhesiolysis is done. ${ }^{8-10}$ Other methods include; pressure lavage under ultrasound guidance and hysterotomy with transfundal adhesiolysis. Endometrial cavity splinting is done using a paediatric Foley's catheter, intrauterine device, stent or tubing. Endometrial regeneration can be improved by cyclical estrogen/progesterone therapy and sildenafil. ${ }^{10}$ Recently also, the use of amnion graft and stem cells from bone marrow and autologous menstrual blood are in small experimental women studies with remarkable results. ${ }^{11,12}$ However the degree of success depends on the severity of adhesion. ${ }^{1}$
This study is aimed at determining the prevalence, clinical presentation and treatment outcome of Asherman's syndrome in our hospital.

\section{METHODS}

This was a retrospective analysis of patient's with Asherman's syndrome managed at the University of Maiduguri teaching hospital over 10 years (January 2008 to December 2017). The cases were identified using Gynaecology ward and theatre records and their case notes retrieved from the medical record department. A proforma design for the study was used to extract data from the case notes. The information extracted included demographic characteristics, the number of miscarriages, presenting complaint, predisposing factor, diagnostic tool used, management offered and outcome of the treatment. Data obtained was analyzed using Microsoft office excel 2007and SPSS version 25 (IBM SPSS, Statistics) to generate descriptive statistics (frequencies, ratio and percentages) which were presented as tables.

\section{RESULTS}

During the study period, 81 patients were managed for Asherman's syndrome with 55 case files available giving a retrieval rate of $67.90 \%$. There were 1521 gynaecological surgeries during the period of the study givinga prevalence of AS of $5.3 \%$ of gynaecological operations. The sociodemographic data of the patients is shown in (Table 1). Most of the patients were in the $25-34$ age group $(69.1 \%)$, followed by the 35 44 age group $(18.2 \%)$. Most of the patients were married $(94.5 \%)$ and a majority (34.5\%).had tertiary education. Dilatation and curettage constituted the commonest risk factor for Asherman's syndrome (21/55, 38.2\%), followed by myomectomy alone $(11 / 55,20.0 \%)$, puerperal infection $10.9 \%(6 / 55)$ and caesarean section $7.3 \%(3 / 55)$ (Table 2). Majority of the patients presented with infertility alone $(29,52.7 \%)$, hypomenorrhea and infertility $10(18.2 \%)$ and recurrent miscarriage $5(9.1 \%)$ (Table 3). The treatment outcome of the patients was as shown in (Table 4). Twenty-five percent of the patients (14/55) achieved normal menses and $11(20 \%)$ achieved pregnancy. About 22 patients $(40 \%)$ were lost to follow up within 6 months of treatment although 18 patients $(32.7 \%)$ were followed up for one year or more (Tables 4-5).

\section{DISCUSSION}

This study revealed a prevalence of Asherman's syndrome of 5.3\% with the age group 25-34 years being the commonest age group and $\mathrm{D}$ and $\mathrm{C}$ the commonest risk factor. The majority of the patients presented with infertility and $20 \%$ achieved pregnancy following treatment. The prevalence of Asherman's syndrome of $5.3 \%$ found in this study is similar to that found in Uyo, Southwestern Nigeria, higher than the $1.6 \%$ reported 
from Abuja and 1.4\% reported from Kano but lower than $29.2 \%$ reported from Lagos Southern Nigeria., $3,4,6,13$

Table 1: Sociodemographic characteristics of the study group.

\begin{tabular}{|lll|}
\hline Parameters & N & $\%$ \\
\hline Age (years) & & \\
\hline $15-24$ & 7 & 12.7 \\
\hline $25-34$ & 38 & 69.1 \\
\hline $35-44$ & 10 & 18.2 \\
\hline Total & 55 & 100.0 \\
\hline Parity & & \\
\hline 0 & 30 & 54.5 \\
\hline $1-4$ & 24 & 43.6 \\
\hline 5 and above & 1 & 1.8 \\
\hline Total & 55 & 100.0 \\
\hline Marital status & & \\
\hline Single & 3 & 5.5 \\
\hline Married & 52 & 94.5 \\
\hline Total & 55 & 100.0 \\
\hline Educational level & & \\
\hline Primary school & 5 & 9.1 \\
\hline Secondary school & 18 & 32.7 \\
\hline Tertiary education & 19 & 34.5 \\
\hline No formal education & 13 & 23.6 \\
\hline Total & 55 & 100.0 \\
\hline Miscarriages & & \\
\hline 0 & 20 & 36.4 \\
\hline 1 & 16 & 29.1 \\
\hline 2 & 11 & 20.0 \\
\hline 3 & 8 & 14.5 \\
\hline Total & 55 & 100.0 \\
\hline & & \\
\hline
\end{tabular}

Table 2: Risk factors of the patients in the study.

\begin{tabular}{|lll|}
\hline Risk factors & N & $\%$ \\
\hline Dilatation and curettage & 21 & 38.2 \\
\hline Myomectomy & 11 & 20.0 \\
\hline Puerperal infection & 6 & 10.9 \\
\hline Non identified & 4 & 7.3 \\
\hline Post caesarean section infection & 4 & 7.3 \\
\hline Caesarean section & 4 & 7.3 \\
\hline Post abortal sepsis & 3 & 5.5 \\
\hline PID & 2 & 3.6 \\
\hline Total & 55 & 100 \\
\hline
\end{tabular}

This varying prevalence maybe because of the variations in the populations studied and the methods of diagnosis employed. For example, hysteroscopy which is more accurate and the gold standard for diagnosis of Asherman's syndrome was used in making the diagnosis in the Lagos study that reported a high prevalence while HSG was the main tool used for making the diagnosis in our study and the study from Kano.
Similar to the reports of other studies majority of the patients in our study were in the age group 25-34 years. $^{3,6,9}$

Table 3: Presenting complaints of the patients.

\begin{tabular}{|lll|}
\hline Presenting complaints & N & $\%$ \\
\hline Infertility & 29 & 52.7 \\
\hline Hypomenorrhea and infertility & 10 & 18.2 \\
\hline Recurrent miscarriages & 5 & 9.1 \\
\hline $\begin{array}{l}\text { Hypomenorrhea, infertility and } \\
\text { cyclical pelvic pain }\end{array}$ & 3 & 5.5 \\
\hline infertility and cyclical pelvic pain & 3 & 5.5 \\
\hline Amenorrhea and infertility & 2 & 3.6 \\
\hline Hypomenorrhaa & 2 & 3.6 \\
\hline Amenorrhea & 1 & 1.8 \\
\hline Total & 55 & 100 \\
\hline
\end{tabular}

Table 4: Treatment outcome of the study population.

\begin{tabular}{|lll|}
\hline Outcomes & N & $\%$ \\
\hline Achieved normal menses & 14 & 25.5 \\
\hline Achieve pregnancy & 11 & 20.0 \\
\hline $\begin{array}{l}\text { Achieve normal menses and relief } \\
\text { in cyclical pain }\end{array}$ & 3 & 5.4 \\
\hline No change in condition & 5 & 9.1 \\
\hline Lost to follow up & 22 & 40.0 \\
\hline Total & 55 & 100.0 \\
\hline
\end{tabular}

Table 5: Duration of follow up.

\begin{tabular}{|lll|}
\hline Outcomes (months) & N & $\%$ \\
\hline $\mathbf{0 - 3}$ & 12 & 21.8 \\
\hline $\mathbf{4 - 5}$ & 21 & 38.2 \\
\hline $\mathbf{6 - 9}$ & 4 & 7.3 \\
\hline $\mathbf{1}$ year and above & 18 & 32.7 \\
\hline Total & 55 & 100.0 \\
\hline
\end{tabular}

This is the most reproductively active age group and the majority of the patients $(94.5 \%)$ were married. They are therefore more likely to be pregnant and develop a pregnancy complication like abortions that can result in uterine evacuations which is a common cause of AS. The commonest risk factor for the development of AS in this study was D\&C. This was similar to the reports of other studies., 3,6,7,9 Endometrial injury induces ischemia and inflammatory reactions that lead to hypoxic cellular modifications and release of active substances leading to fibrosis and $\mathrm{D} \& \mathrm{C}$ is traumatic to the endometrium. ${ }^{14,15}$ The other risk factors identified including myomectomy and caesarean sections may have operated through the same trauma to the endometrium that can occur during these procedures. Although similar to the report of Charles et al infectious complications (post abortal and puerperal infections) were found to be risk factors of AS, the role of infection in the pathogenesis of AS remains unclear and Polishuk et al reported that the development 
of endometritis after caesarean delivery is not associated with increased incidence of AS. 6,16

Patients with AS usually present with menstrual problems (hypomenorrhea or amenorrhea) and/or infertility, and similar to other studies the commonest presentation of the patients in our study was menstrual problems and/or infertility. ${ }^{6,7,17}$ Intrauterine adhesions causereduction of the endometrial surface and therefore bleeding area leading to menstrual problems and AS is associated with endometrial trophic changes and unresponsiveness that can result in infertility. The treatment of the AS in our centre is done following a carefully developed departmental protocol that consists of $\mathrm{D}$ and $\mathrm{C}$, insertions of size 14G Foley's catheter for 10 days, endometrial restoration with estrogen and post-operative antibiotics, although hysteroscopic resection has started in the last 2 years of the study period. Following treatment, $20 \%$ of our patients achieve pregnancy. This was higher than the $10.2 \%$ pregnancy rate reported by Opadiran et al from Abuja, Nigeria but lower than the $29 \%$ reported by Njoku et al, $27.3 \%$ reported by Shiktra et al and the $26.6 \%$ reported by Bhandari et al. ${ }^{6,7,18}$ The slightly lower pregnancy rate in our study compared to the other studies in our environment may be because $40 \%$ of our patients were lost to follow up within six of treatment although $37.2 \%$ of our patients were followed up for a year or more. Pregnancy rates ranging between 56 to $76 \%$ has been reported in patients with AS treated with hysteroscopic adhesiolysis. ${ }^{19,20}$ Hysteroscopy has become the gold standard for the treatment of AS, as it is safer and more effective compared to D and C. With a laparoscope the adhesions can be viewed directly and the magnification provided by the instrument allows accurate division of the adhesions to restore normal uterine calibre and free tubal Ostia in comparison to blind D and C.

\section{CONCLUSION}

AS is not uncommon in our environment and it is usually associated with activities that result in endometrial injury. The commonest presentation is a menstrual abnormality and/or infertility which can be ameliorated with intrauterine adhesiolysis.

Funding: No funding sources

Conflict of interest: None declared

Ethical approval: The study was approved by the Institutional Ethics Committee

\section{REFERENCES}

1. Amenorrhea, In; Hoffman, Schoffer, Bradshaw, Schorge, Halvorson, Cunningham(ed). Williams Gynaecology, 2nd ed. United States of America: McGraw-Hill companies Inc; 2012:16;440-57.

2. Alex S, Wendy YC, Alan HD. In; Decherney AH, Nathan L, Laufer N, Ashley RS eds. Current diagnosis and treatment, Obstetric and gynaecology. 11th ed. United States of America: McGraw-Hill companies Inc; 2013:54;889-99.

3. Opadiran RO, Isah AD, Agida ET, Adewole N. Outcome of intrauterine adhesion management at a Nigerian tertiary hospital; a five year review. Int $\mathbf{J}$ Reprod Contracept Obstet Gynecol. 2018;7:375-9.

4. Ajayi A B, Afolabi B M, Ajayi V, Biobaba O, et al. Risk factors for intrauterine adhesions in a black African population. Nigerians. Gynecol Obstet. 2017; 7:436.

5. Chanrit P, Tawiwan P, Opas S, Usanee S. Intrauterine adhesions: causes and treatment outcomes among Thai women. J med Assoc Thai. 2016;99(10):106772.

6. Charles N, Cahethan E, Edu E, Boniface A, John E. Risk factors and management outcome of intrauterine adhesion in a constrained socioeconomic environment: a 10 year review in the university of Calabar teaching hospital, Calabar. EJPM. 2017;4(3): 25-30.

7. Kwari SD, Idrisa A. Intrauterine adhesions at the university of Maiduguri teaching hospital, Maiduguri, Nigeria. A 3 year review. Trop J Obstet Gynecol. 2011;28(10):50-1.

8. Saroja CSM, Nankani A, El-Hamamy E. Uterine compression sutures,an update:review of efficacy, safety and complications of B-Lynch suture and other uterine compression techniques for postpartum haemorrhage. Arch Gynecol Obstet. 2010;281(4):5818.

9. Utuk N, Abasiattai A M, Asuquo O. Intrauterine adhesion in the university of Uyo teaching hospital, south-south, Nigeria. A 10 year review. Trop J Obstet Gynecol. 2019;6:39-43

10. Dreisler E, Kjer JJ. In Asherman's syndrome;current perspectives on diagnosis and management. Int $\mathbf{J}$ Women's Health. 2019;11:191-8.

11. Neeta S, Sujata M, Sona D. Autologous stem cell transplantation in refractory Asherman's syndrome: A novel cell based therapy. J Hum Reprod Sci. 2014; 7(2):93-8.

12. Changjiang L, Jia W. The study on the safety and efficacy of amnion graft for preventing the recurrence of moderate to severe intrauterine adhesions. Genes Dis. 2020;7(2):266-71.

13. Gaya SA, Adamu IS, Yakasai IA. Review of intrauterine adhesiolysis at the Aminu Kano Teaching Hospital, Kano, Nigeria. Ann Afr Med. 2012;11(2): 65-9.

14. Yu D, Wong YM, Cheong Y, Xia E, Li TC. Asherman syndrome-one century later. Fertil Steril. 2008;89:759-79.

15. Chen Y, Chang Y, Yao S. Role of angiogenesis in endometrial repair of patients with severe intrauterine adhesion. Int J Clin Exp Pathol. 2013;15:1343-50.

16. Polishuk WZ, Anteby SO, Weinstein D: Puerperal endometritis and intrauterine adhesions. Int Surg. 1975;60:418-20.

17. Abiodun OM, Balogun OR, Fawole AA. Aetiology, clinical features and treatment outcome of intrauterine 
adhesion in Ilorin, Central Nigeria. West Afr J Med. 2007;26:298-301.

18. Bhandari Sh, Bhave P, Ganguly I, Baxi A, Agarwal P. Reproductive Outcome of Patients with Asherman's Syndrome: A SAIMS Experience. J Reprod Infertil. 2015;16(4):229-35.

19. Valle RF, Sciarra JJ. Intrauterine adhesions: hysteroscopic diagnosis, classification, treatment, and reproductive outcome. Am J Obstet Gynecol. 1988; 158(6):1459-70.
20. Yamamoto N, Takeuchi R, Izuchi D. Hysteroscopic adhesiolysis for patients with Asherman's syndrome: menstrual and fertility outcomes. Reprod Med Biol. 2013;12(4):159-66.

Cite this article as: Geidam $\mathrm{AD}$, Malgwi $\mathrm{A}$.

Ten-year review of the clinical presentation and treatment outcome of Asherman's syndrome in university of Maiduguri teaching hospital, Borno State, Nigeria. Int J Reprod Contracept Obstet Gynecol2022;11:704-8. 